Supplement of The Cryosphere, 10, 2057-2068, 2016

http://www.the-cryosphere.net/10/2057/2016/

doi:10.5194/tc-10-2057-2016-supplement

(C) Author(s) 2016. CC Attribution 3.0 License.

(c) (i)

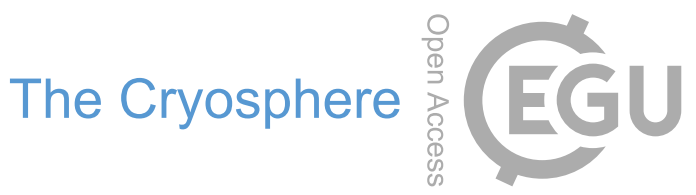

Supplement of

\title{
Direct visualization of solute locations in laboratory ice samples
}

Ted Hullar and Cort Anastasio

Correspondence to: Cort Anastasio (canastasio@ucdavis.edu)

The copyright of individual parts of the supplement might differ from the CC-BY 3.0 licence. 
Supplemental materials are available at:

http://dx.doi.org/10.1594/PANGAEA.855461

\section{Captions for supplementary information}

Note: On some monitors, the color labeled "orange" in the movie legends may appear more yellow than orange.

S1: Movie of pure water, frozen in the Freezer.

S2: Movie of pure water, degassed with helium, frozen in the Freezer.

S3: Movie of $1 \mathrm{mM}$ cesium chloride $(\mathrm{CsCl})$ solution, frozen in the Freezer.

S4: Movie of $1 \mathrm{mM}$ cesium chloride $(\mathrm{CsCl})$ solution, frozen in the Freeze Chamber.

S5: Movie of $1 \mathrm{mM}$ cesium chloride $(\mathrm{CsCl})$ solution, frozen in the Freeze Chamber, with the sample vial surrounded by metal plates.

S6: Movie of $1 \mathrm{mM}$ cesium chloride ( $\mathrm{CsCl}$ ) solution, frozen in Liquid Nitrogen (LN2). There is one visible deformity in the side of the ice sample, which is caused by a defect in the sample vial wall.

S7: Single high-resolution $(2 \mu \mathrm{m})$ cross section of $1 \mathrm{mM} \mathrm{CsCl}$ solution, frozen in $\mathrm{LN} 2$, showing small air and solute inclusions.

S8: Chemical structure of Rose Bengal.

S9: Movie of $1 \mathrm{mM}$ Rose Bengal solution, frozen in the Freeze Chamber.

S10: Histogram of three replicate samples of $1 \mathrm{mM} \mathrm{CsCl}$ solution frozen in the Freeze Chamber.

S11: Movie of pure water, frozen in the Freeze Chamber.

S12: Movie of pure water, frozen in the Freeze Chamber, in a plastic vial.

S13: Movie of $1 \mathrm{mM}$ cesium chloride $(\mathrm{CsCl})$ solution, frozen in the Freeze Chamber, in a plastic vial.

S14: Movie of $1 \mathrm{mM}$ Rose Bengal solution, frozen in the Freeze Chamber, in a plastic vial.

S15: Movie of $1 \mathrm{mM} \mathrm{CsCl}$ solution, frozen in the Freezer, showing side-by-side images at both $2 \mu \mathrm{m}$ and $16 \mu \mathrm{m}$ resolutions.

S16: Time-lapse movie of $1 \mathrm{mM} \mathrm{CsCl}$ solution, frozen in the Freezer, $2 \mu \mathrm{m}$ resolution, showing motion of $\mathrm{CsCl}$ solution around air bubbles. 
